\title{
DISTRIBUTION COEFFICIENTS FOR CHEMICAL COMPONENTS OF A COAL-OIL/WATER SYSTEM
}

\author{
Kurt C. Picel', Vassilis C. Stamoudis ${ }^{1 *}$ and Milagros S. Simmons ${ }^{2}$ \\ 'Center for Environmental Research, Biological, Environmental, and Medical Research Division, \\ Argonne National Laboratory, Argonne, IL 60439 and ${ }^{2}$ Department of Environmental and Industrial \\ Health, The University of Michigan, Ann Arbor, MI 48109, U.S.A.
}

(First received November 1987, accepted in revised form April 1988)

\begin{abstract}
Distribution coefficients $\left(K_{\mathrm{D}} s\right)$ were measured by equilibrating a coal oil comparative reference material (CRM-1) with water and then separating the oil and water phases. Aqueous phase concentrations were determined by direct analysis of this phase, while organic phase concentrations were determined from the original oil composition by difference. The $\log K_{\mathrm{D}}$ values obtained for acidic and basic components were generally $<3$, while those for the neutral components ranged from 3 to 6 . For aromatic hydrocarbons, strong correlations were observed between $\log K_{\mathrm{D}}$ and $\log S_{\mathrm{w}}$ (water solubility), and between $\log K_{\mathrm{D}}$ and $\log K_{\mathrm{ow}}$ (octanol/water partition coefficient). Alkylated benzenes had significantly higher $K_{\mathrm{D}} \mathrm{s}$ than did unsubstituted aromatics of similar molecular weight. Examination of homologs revealed an increase of $0.307 \log K_{\mathrm{D}}$ units per additional carbon atom for polynuclear aromatic hydrocarbons having from 10 to 16 carbons. Alkyl substituent effects determined for various sets of homologs ranged from 0.391 to $0.466 \log K_{\mathrm{d}}$ units per $-\mathrm{CH}_{2}-$ group added.
\end{abstract}

Key words-distribution coefficients, $K_{\mathrm{D}}, K_{\mathrm{ow}}$, coal oil, coal-oil partitioning, PAH

\section{INTRODUCTION}

Coal oil produced through liquefaction is an important potential energy resource for meeting future energy needs. Toxicity studies of coal-oil-related materials have indicated that significant health and environmental hazards would be associated with large-scale production and transport of coal oil. In particular, acute and chronic toxicities in aquatic systems were found to be much more severe for coal oil than for petroleum products. Toxicity has been correlated to the high water solubility of many coaloil components such as phenols, anilines and pyridines (Dauble et al., 1981; Giddings and Washington, 1981; Gray et al., 1982; Giddings et al., 1985). Therefore, knowledge of the behavior and persistence of these materials in aquatic systems is important for evaluating hazards associated with the commercialization of coal conversion processes.

The distribution coefficient, $K_{\mathrm{D}}$, is a useful parameter for assessing the transport and persistence of pollutants in aquatic systems. It can be used to estimate aqueous concentrations of contaminants and to predict bioconcentration factors and environmental toxicities for specific pollutants (Neely et al., 1974; Chiou et al., 1977; Hansch, 1980; Chiou, 1985). $K_{\mathrm{D}}$ has also been shown to be important for predicting the rates (Herbes et al., 1983) and extent (Southworth and Keller, 1984) of dissolution of organic

*Author to whom correspondence should be addressed. constituents of coal-oil films and sludges into water, and for designing water treatment systems for synthetic fuel and coal-coking wastewater streams (Walters and Luthy, 1984a, b).

Coal oils are extremely complex organic materials that contain acidic (phenols), neutral [polynuclear aromatic hydrocarbons $(\mathrm{PAH})$ and $\mathrm{N}-, \mathrm{O}-$, and S-heterocyclic compounds] and basic (amines and azaarenes) components. Aqueous solutions produced by equilibrating coal oil with water contain these chemical classes in much different proportions than in the original oils due to differential partitioning (Picel, 1985). Polar components are greatly enriched in the aqueous phase with respect to nonpolar components. As a result, phenols, anilines, pyridines and, to a lesser extent, 1- to 2-ring aromatic hydrocarbons predominate in aqueous solutions.

In this study, $K_{\mathrm{D}}$ values were measured for a large number of components of the major chemical classes of a coal oil reference material, CRM-1. After CRM1 was equilibrated with water, the aqueous phase was isolated and analyzed. Oil phase concentrations were obtained from analysis of the original oil by difference.

Partitioning of PAH and alkylated benzenes was examined in detail because of particular interest in their toxicity and complex behavior in aquatic systems, and for the purpose of understanding the thermodynamics of the coal-oil/water system. Using data for homologs, the thermodynamics of partitioning of PAH and alkylated benzenes is probed 
through correlations of $K_{\mathrm{D}}$ with water solubility, $S_{\mathrm{w}}$, and with $K_{\text {ow }}$, the distribution coefficient in the octanol/water system. In addition, partitioning of coal-oil PAH as components of a complex organic mixture is discussed, and aqueous phase activity coefficients are compared to reported values.

\section{EXPERIMENTAL APPROACH}

\section{Materials}

CRM-1 was obtained from the U.S. Department of Energy/U.S. Environmental Protection Agency Fossil Fuels Research Materials Facility at Oak Ridge National Laboratory. Chemical standards ( $>97 \%$ pure) were purchased, with few exceptions, from Aldrich Chemical Co., Inc. (Milwaukee, Wis.), and were used without further purification. Silica gel (100/120 mesh) was purchased from Alltech Associates, Inc. (Deerfield, Ill.) and alumina (80/200 mesh, Brockman Activity I) was purchased from Fisher Scientific Co. (Pittsburgh, Pa). High-purity water was prepared by passing distilled water through an activated carbon column. Solvents were high-purity grade and were purchased from Burdick and Jackson Laboratories, Inc. (Muskegon, Mich.).

\section{Equilibration}

Equilibrated coal-oil/water solutions were prepared by adding raw CRM-1 to water ( $\left.2 \mathrm{gl}^{-1}\right)$ in 1-gal solvent bottles and stirring the solutions constantly with a magnetic stirring bar for 5 days at room temperature $\left(21^{\circ} \mathrm{C}\right)$. A large waterto-oil ratio was chosen to simulate a spill condition, and to provide sufficient aqueous sample for analysis. The 5-day mixing period was assumed to be sufficient to attain equilibrium based on preliminary data for phenanthrene, which showed no increase in aqueous concentration between 5 and 24 days of mixing. The $\mathrm{pH}$ of the solution was near neutral. Extreme $\mathrm{pH}(<4$ and $>10)$ would affect the partitioning of acidic or basic species, but little effect is expected in the normal range of environmental $\mathrm{pH}$.

After equilibration, the coal and aqueous phases were separated by passing the mixture through a coarse glass frit and then through a $0.45-\mu \mathrm{m}$ membrane filter (type HA, Millipore Corporation, Bedford, Mass.) for final clarification of the mixture. The resulting solution was clear and colorless, and contained no visible oil droplets.

As pointed out by Walters and Luthy (1984b), filtering through a $0.45-\mu \mathrm{m}$ filter represents an operational definition of the two dissimilar phases produced (oil and water in this case and suspended solids and water in their case). While acknowledging this fact, the thermodynamic data obtained in this study suggest that a good separation of phases was effected by this technique. Losses due to sorption to the filtering apparatus were minimized by filtering a large amount of sample in each pass. Small losses have a minimal effect on $\log K_{\mathrm{D}}$ which is used in thermodynamic correlations.

\section{pH fractionation}

Acidic, basic and neutral components were isolated by $\mathrm{pH}$-adjusted liquid/liquid extraction (Stamoudis and Luthy, 1980). Basic and neutral components of the aqueous oil samples were extracted with $\mathrm{CH}_{2} \mathrm{Cl}_{2}$ after $\mathrm{pH}$ adjustment of the sample to $\geqslant 12$ using $\mathrm{NaOH}$. The acidic components were then extracted from the high $\mathrm{pH}$ aqueous layers with $\mathrm{CH}_{2} \mathrm{Cl}_{2}$, after lowering the $\mathrm{pH}$ to $\leqslant 2$ with $\mathrm{HCl}$. The basic components were isolated from the basic/neutral extract by partitioning with aqueous $\mathrm{HCl}(\mathrm{pH} \leqslant 2)$. (The $\mathrm{CH}_{2} \mathrm{Cl}_{2}$ layer contained the neutral components.) This procedure was followed by back extraction of the bases from the aqueous phase with $\mathrm{CH}_{2} \mathrm{Cl}_{2}$, after adjusting its $\mathrm{pH}$ to $\geqslant 12$ with $\mathrm{NaOH}$. The same fractionation procedure was used for the raw oil samples, except that the sample material was first dissolved in $\mathrm{CH}_{2} \mathrm{Cl}_{2}$ and the acidic components were partitioned into an aqueous $\mathrm{NaOH}$ phase.

\section{Adsorption chromatography}

The neutral components from the $\mathrm{pH}$ fractionation step were subfractioned into major chemical classes on silica gel Silica gel $\left(10 \mathrm{~g}, 150^{\circ}\right.$ activation) was packed dry into a $1 \times 40 \mathrm{~cm}$ glass chromatography column, and then wetted with $\mathrm{CH}_{2} \mathrm{Cl}_{2}$ and preeluted with $40 \mathrm{ml}$ pentane. The neutral fraction (not more than $350 \mathrm{mg}$ ) was exchanged into cyclohexane $(2 \mathrm{ml})$ and added to the head of the column. Four polarity fractions (B1-B4) were then eluted with the following eluents: $20 \%(\mathrm{v} / \mathrm{v}) \mathrm{CH}_{2} \mathrm{Cl}_{2}$ in pentane $(\mathrm{Bl}), 40 \%(\mathrm{v} / \mathrm{v})$ $\mathrm{CH}_{2} \mathrm{Cl}_{2}$ in pentane (B2), ethyl ether (B3) and methanol (B4). Fraction $\mathrm{B} 1$ contained the aliphatic and aromatic hydrocarbons and B2 contained the neutral azaarenes. Fractions B3 and B4 represented two higher polarity cuts that were not characterized in detail.

A 4- to 6-ring PAH fraction was isolated from the B fraction of the original oil sample on an alumina $(10 \mathrm{~g}, 2 \%$ water deactivated) column. The sample was added to the column in cyclohexane. The aliphatic and 1- to 3-ring aromatic hydrocarbons $(\mathrm{CI})$ were then eluted with $10 \%$ ( $v / v) \mathrm{CH}_{2} \mathrm{Cl}_{2}$ in pentane, followed by elution of the 4- to 6-ring $\mathrm{PAH}(\mathrm{C} 2)$ with $60 \%(\mathrm{v} / \mathrm{v}) \mathrm{CH}_{2} \mathrm{Cl}_{2}$ in pentane.

Figure 1 is a schematic diagram of the overall fractionation procedure. The distribution of sample mass among the various fractions from adsorption chromatography and from the initial $\mathrm{pH}$ fractionation step was determined by microgravimetry, using a CAHN 25 Electrobalance for both the raw-oil and aqueous-oil samples.

\section{GC/MS analysis}

Fraction components were identified using electronimpact GC/MS [Hewlett Packard (HP) Model 5984A mass spectrometer equipped with an HP Model 5934A data system and an HP Model 5840A GC]. Spectra were obtained from 40 to 320 a.m.u. with an ionization energy of $70 \mathrm{eV}$ and a source temperature of $170^{\circ} \mathrm{C}$. The $\mathrm{GC}$ was equipped with a split/splitless injector $\left(280^{\circ} \mathrm{C}\right)$, a heated transfer line $\left(250^{\circ} \mathrm{C}\right)$ and a cryogenic unit for subambient cooling. Injections were made in the splitless mode. Separations were performed on a $50 \mathrm{~m} \times 0.32 \mathrm{~mm}$ i.d. fused silica capillary column with an OV-101 stationary phase, using helium as the carrier gas. The temperature program consisted of a 2 -min hold at $30^{\circ} \mathrm{C}$, followed by a $4^{\circ} \mathrm{C} \mathrm{min}^{-1}$ ramp to $270^{\circ} \mathrm{C}$, which was held for $20 \mathrm{~min}$. Spectra were identified by comparison with standard reference spectra. Isomers of the numerous alkyl-substituted compounds were identified by alkyl carbon number and elution order, due to the unavailability of specific standards.

\section{$G C$ analysis}

The multiple fractions produced were analyzed on an HP 5880A GC equipped with a split/splitless injector, a flame ionization detector (FID) and a Level Four BASIC data system. Column and oven conditions were the same as those described for GC/MS analysis.

The GC runs were automatically processed by the GC data system, which used a calibration table created from GC/MS identifications to locate and quantify sample constituents. Quantification was based on response factors determined by using a representative standard for each fraction. This approach was possible because of the homogeneous chemical composition of the fractions analyzed and the uniform response of the FID to members of the same chemical class (Tong and Karasek, 1984). Furthermore, exact response factors are not required for measurements of $K_{\mathrm{D}}$. The GC analysis reports were transferred electronically to an IBM 3033 mainframe computer, where the data were processed using Statistical Analysis Systems (SAS) programming. 
FRACTIONATION PROCEDURE

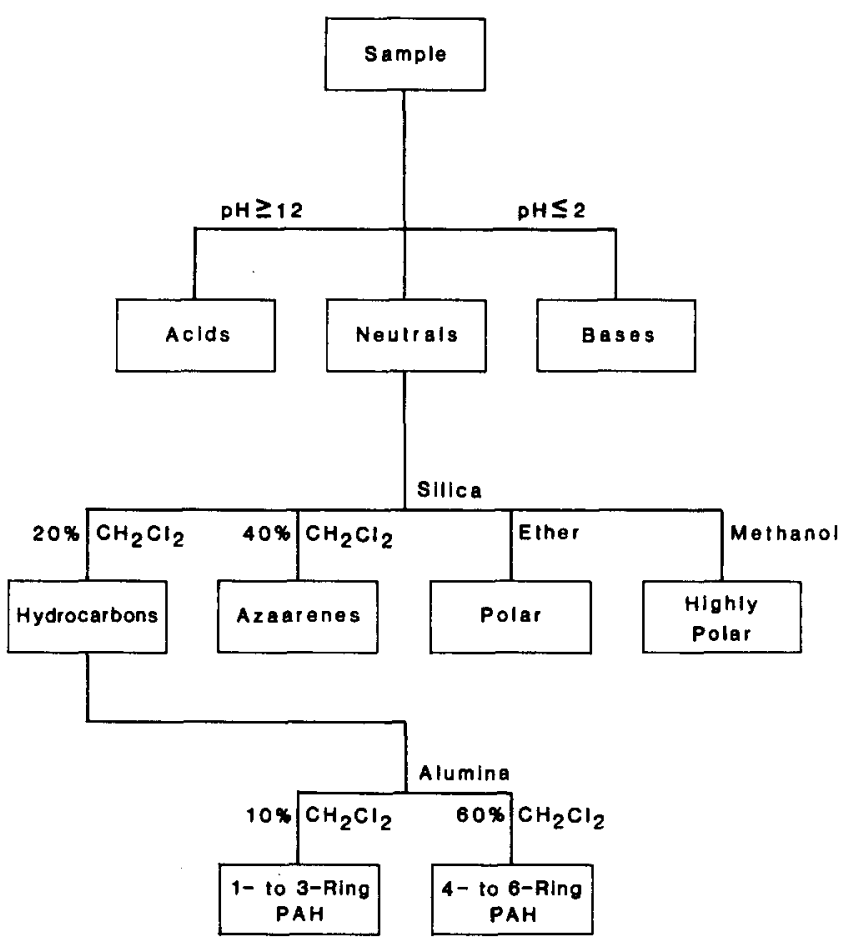

Fig. 1. Sample fractionation procedure.

\section{EXPERIMENTAL RESULTS}

\section{Bulk composition}

The distribution of CRM-1 sample mass among the acid, base and neutral fractions and among the neutral fraction subfractions from silica gel is given in Table 1 for both the raw-oil and aqueous-phase samples. The bulk of the raw oil is made up of neutral components, of which $>75 \%$ are hydrocarbons, and of which $>90 \%$ are aromatic. The neutral azaarene fraction and the two higher polarity fractions are relatively minor subfractions. Approximately $60 \%$ of the oil is accounted for by the GC analysis. The remaining $40 \%$ is nonrecoverable or nonchromatographable material.
The acidic components are the next largest fraction of oil, and consist mostly of $\left(\mathrm{C}_{0}-\mathrm{C}_{3}\right)$-phenols. Some of the more alkylated $\left(\mathrm{C}_{3}-\mathrm{C}_{6}\right)$-phenols appear in the ether subfraction (B3) of the neutral components. The basic fraction represents a relatively small percentage of the oil and is made up primarily of pyridines, anilines and quinolines.

The distribution of mass in the aqueous phase is much different from that in the original oil (Table 1, columns 1 and 2). The acidic components (phenols) are enriched with respect to the original oil and are clearly predominant. Conversely, the percentage of total mass of the neutral fraction in the aqueous phase is reduced by a factor of three with respect to that of the original oil. More significantly, its hydro-

Table 1. Composition of CRM-1 and aqueous CRM-1 by fraction

\begin{tabular}{lcccc}
\hline & Composition of CRM-1 (wt \%) & $\begin{array}{c}\text { Conc. in } \\
\text { aqueous } \\
\text { phase } \\
\left(\mathrm{mg} \mathrm{l}^{-1}\right)\end{array}$ & $\begin{array}{c}\text { \% Total } \\
\text { in aqueous } \\
\text { phase }\end{array}$ \\
\hline Fraction & Raw oil & Aqueous phase* & 314 & 71 \\
\hline Acid & 22 & 70 & 37 & 35 \\
Base & 5.3 & 8.2 & 97 & 7.4 \\
Neutral & 66 & 22 & 4.8 & 0.47 \\
$\quad$ Hydrocarbons (B1) & 51 & 1.1 & 12 & 25 \\
Azaarenes (B2) & 2.3 & 2.6 & 66 & 32 \\
Ether (B3) & 10 & 15 & 14 & $19 \dagger$ \\
Methanol (B4) & 3.6 & 3.1 & & \\
\hline
\end{tabular}

*Raw CRM-1 was equilibrated with water at $2 \mathrm{gl}^{-1}$.

tThis value is probably low because of the low extractability of this fraction from water. 
Table 2. Log $K_{\mathrm{D}}$ values for acidic components of CRM-1

\begin{tabular}{|c|c|c|c|c|}
\hline Compound & $\begin{array}{l}\text { Concentration } \\
\text { in raw CRM-1 } \\
\left(\mu \mathrm{g} \mathrm{g}^{-1}\right)\end{array}$ & $\begin{array}{c}\text { Concentration } \\
\text { in aqueous } \\
\text { phase } \\
\left(\mathrm{mg} \mathrm{l}^{-1}\right)\end{array}$ & $\begin{array}{l}\text { Amount } \\
\text { transferred } \\
\text { to aqueous } \\
\text { phase } \\
(\%)\end{array}$ & $\log K_{\mathrm{D}} *$ \\
\hline Phenol & $18,900 \pm 700$ & $33.8 \pm 1.6$ & 89 & - \\
\hline$o$-Cresol & $11,600 \pm 300$ & $25.1 \pm 0.4$ & 108 & - \\
\hline$(m+p)$-Cresols & $38,600 \pm 950$ & $81.4 \pm 1.7$ & 105 & - \\
\hline $\mathrm{C}_{2}$-phenols (8) $\dagger$ & $49,000 \pm 800$ & $102.0 \pm 0.5$ & 103 & - \\
\hline $\mathrm{C}_{3}$-phenols (11) & $30,000 \pm 600$ & $51.3 \pm 0.2$ & 86 & - \\
\hline $\mathrm{C}_{4}$-phenols (3) & $8440 \pm 190$ & $8.64 \pm 0.25$ & 51 & $2.79 \pm 0.06$ \\
\hline Hydroxyindans (2) & $14,400 \pm 300$ & $25.7 \pm 0.1$ & 89 & - \\
\hline $\mathrm{C}_{1}$-hydroxyindans $(10)$ & $15,500 \pm 350$ & $17.2 \pm 0.3$ & 55 & $2.71 \pm 0.06$ \\
\hline $\mathrm{C}_{2}$-hydroxyindans (3) & $5570 \pm 190$ & $4.67 \pm 0.06$ & 42 & $2.95 \pm 0.06$ \\
\hline
\end{tabular}

*Values were not reported for components having $>80 \%$ of their mass in the aqueous phase. tThe number of GC peaks observed for a set of isomers is given in parentheses.

carbon subfraction (B1) is reduced almost 50 -fold. The relative contributions of the basic fraction and the polar neutral subfractions (B2-B4), are about the same in both the aqueous and oil phases.

\section{Distribution coefficients}

The $K_{\mathrm{D}}$, which is defined here as the equilibrium concentration of component $i$ in the oil phase divided by that in the aqueous phase, was determined from the following equation:

$$
K_{\mathrm{D}}=\frac{\left.\frac{\left(\text { mass } i_{\mathrm{oil}}\right)-\left(\text { mass } i_{\mathrm{aq}}\right)}{\text { (mass oil } \left.{ }_{\text {orig }}\right)-(\text { mass oil }} \text { aq }_{\mathrm{aq}}\right)}{\left(\text { conc } i_{\mathrm{aq}}\right)} .
$$

The aqueous-phase concentrations (conc. $i_{\mathrm{aq}}$ ) of each component were measured directly. The concentrations in the corresponding equilibrated-oil phase were calculated from the amount of each component in the original oil (mass $i_{\text {oil }}$ ) by subtracting the amount of the component found in the aqueous phase (mass $i_{\mathrm{aq}}$ ) and then dividing by the mass of the original oil less the amount of oil that dissolved in the aqueous phase $(22 \%)$.
This approach was suitable for relatively insoluble components, but was not applicable when $>80 \%$ of a component was in the aqueous phase. Above this level, the concentration of the component in the oil phase had an unacceptably high uncertainty based on an average precision for individual concentration measurements of $5.2 \%$. The $80 \%$ level corresponds to a $\log K_{\mathrm{D}}$ lower limit of 2.2 determinable by this technique. In cases involving highly soluble acidic and basic components, $K_{\mathrm{D}}$ values are not reported.

Tables 2 and 3 list the major components of the acid and base fractions, respectively, and present their concentrations in raw CRM-1 and in aqueous CRM-1, and their corresponding $\log K_{\mathrm{D}}$ values. The data for alkyl-substituted isomers were combined for a given alkyl-substitution number so that the distribution behavior of the isomeric groups as a whole could be better represented, and because it was not possible to identify more than a few specific isomers.

The acid fraction consisted almost entirely of $\left(\mathrm{C}_{0}-\mathrm{C}_{4}\right)$-phenols. Because of their high water solubilities, few of the acidic components had measurable $K_{\mathrm{D}}$ values $\left(\log K_{\mathrm{D}}>2.2\right)$. In the base fraction, pyri-

Table 3. $\log K_{\mathrm{D}}$ values for basic components of CRM+1

\begin{tabular}{|c|c|c|c|c|}
\hline Compound & $\begin{array}{l}\text { Concentration } \\
\text { in raw CRM-1 } \\
\left(\mu \mathrm{g} \mathrm{g}^{-1}\right)\end{array}$ & $\begin{array}{l}\text { Concentration } \\
\text { in aqueous } \\
\text { phase } \\
\left(\mathrm{mg} \mathrm{l}^{-1}\right)\end{array}$ & $\begin{array}{c}\text { Amount } \\
\text { transferred } \\
\text { to aqueous } \\
\text { phase } \\
(\%)\end{array}$ & $\log K_{\mathrm{D}}^{*}$ \\
\hline Aniline & $857 \pm 25$ & $1.61 \pm 0.09$ & 94 & - \\
\hline 2-methylaniline & $1830 \pm 40$ & $3.65 \pm 0.12$ & 100 & - \\
\hline 3-methylaniline & $509 \pm 15$ & $0.86 \pm 0.05$ & 82 & $\ldots$ \\
\hline 4-methylaniline & $1100 \pm 30$ & $2.15 \pm 0.12$ & 97 & - \\
\hline $\mathrm{C}_{2}$-anilines $(6) \dagger$ & $3110 \pm 40$ & $5.30 \pm 0.12$ & 85 & - \\
\hline $\mathrm{C}_{3}$-anilines (5) & $1410 \pm 50$ & $1.65 \pm 0.03$ & 58 & $2.66 \pm 0.09$ \\
\hline$C_{1}$-pyridines $(3)$ & $220 \pm 40$ & $0.53 \pm 0.02$ & 120 & - \\
\hline $\mathrm{C}_{2}$-pyridines (6) & $710 \pm 30$ & $1.18 \pm 0.02$ & 83 & - \\
\hline $\mathrm{C}_{3}$-pyridines (5) & $460 \pm 60$ & $0.90 \pm 0.02$ & 99 & - \\
\hline $\mathrm{C}_{4}$-pyridines (2) & $220 \pm 10$ & $0.28 \pm 0.01$ & 63 & $2.57 \pm 0.11$ \\
\hline Quinoline & $1660 \pm 60$ & $1.84 \pm 0.04$ & 56 & $2.71 \pm 0.08$ \\
\hline$C_{1}$-quinolines (4) & $4220 \pm 130$ & $3.52 \pm 0.07$ & 40 & $3.00 \pm 0.06$ \\
\hline $\mathrm{C}_{2}$-quinoline & $1120 \pm 60$ & $0.34 \pm 0.01$ & 15 & $3.55 \pm 0.07$ \\
\hline Tetrahydroquinolines (5) & $2170 \pm 50$ & $2.21 \pm 0.04$ & 51 & $2.79 \pm 0.05$ \\
\hline$C_{1}$-tetrahydroquinolines (6) & $1940 \pm 70$ & $1.40 \pm 0.06$ & 36 & $3.06 \pm 0.08$ \\
\hline Indoline & $180 \pm 10$ & $0.20 \pm 0.01$ & 57 & $2.69 \pm 0.09$ \\
\hline
\end{tabular}

*Values were not reported for components having $>80 \%$ of their mass in the aqueous phase.

tThe number of GC peaks observed for a set of isomers is given in parentheses. 
Table 4. $\log K_{\mathrm{D}}$ values for aromatic hydrocarbon components of CRM-1

\begin{tabular}{|c|c|c|c|c|}
\hline Compound & $\begin{array}{c}\text { Concentration } \\
\text { in raw CRM-1 } \\
\left(\mu \mathrm{gg}^{-1}\right)\end{array}$ & $\begin{array}{l}\text { Concentration } \\
\text { in aqueous } \\
\text { phase } \\
\left(\mathrm{mg} \mathrm{l}^{-1}\right)\end{array}$ & $\begin{array}{c}\text { Amount } \\
\text { transferred } \\
\text { to aqueous } \\
\text { phase } \\
(\%)\end{array}$ & $\log K_{\mathrm{D}} *$ \\
\hline Toluene & $230 \pm 10$ & $0.0162 \pm 0.0010$ & 3.5 & $4.25 \pm 0.07$ \\
\hline $\mathrm{C}_{2}$-benzenes $(3) \dagger$ & $3070 \pm 70$ & $0.0951 \pm 0.0033$ & 1.6 & $4.61 \pm 0.05$ \\
\hline $\mathrm{C}_{3}$-benzenes (5) & $8290 \pm 250$ & $0.0896 \pm 0.0019$ & 0.54 & $5.07 \pm 0.04$ \\
\hline $\mathrm{C}_{4}$-benzenes $(3)$ & $5060 \pm 140$ & $0.0145 \pm 0.0004$ & 0.14 & $5.65 \pm 0.04$ \\
\hline Indan & $4410 \pm 140$ & $0.166 \pm 0.004$ & 1.9 & $4.53 \pm 0.04$ \\
\hline $\mathrm{C}_{1}$-indans (2) & $6440 \pm 140$ & $0.0525 \pm 0.0012$ & 0.41 & $5.20 \pm 0.03$ \\
\hline Naphthalene & $25,900 \pm 800$ & $1.63 \pm 0.07$ & 3.1 & $4.30 \pm 0.06$ \\
\hline 1-methylnaphthalene & $8770 \pm 390$ & $0.182 \pm 0.006$ & 1.03 & $4.79+0.06$ \\
\hline 2-methylnaphthalene & $42,900 \pm 1400$ & $0.775 \pm 0.028$ & 0.90 & $4.85 \pm 0.05$ \\
\hline $\mathrm{C}_{2}$-naphthalenes $(8)$ & $48,900 \pm 1200$ & $0.234 \pm 0.003$ & 0.24 & $5.43 \pm 0.03$ \\
\hline$C_{3}$-naphthalenes (2) & $14,400 \pm 800$ & $0.0260 \pm 0.0006$ & 0.09 & $5.85 \pm 0.06$ \\
\hline $\mathrm{C}_{4}$-naphthalene & $5600 \pm 430$ & $0.0071 \pm 0.0002$ & 0.06 & $6.01 \pm 0.08$ \\
\hline Tetrahydronaphthalenes (3) & $26,200 \pm 500$ & $0.394 \pm 0.005$ & 0.75 & $4.93 \pm 0.02$ \\
\hline $\mathrm{C}_{1}$-tetrahydronaphthalenes $(10)$ & $41,500 \pm 700$ & $0.175 \pm 0.002$ & 0.21 & $5.48 \pm 0.02$ \\
\hline $\mathrm{C}_{2}$-tetrahydronaphthalene & $4700 \pm 400$ & $0.0090 \pm 0.0003$ & 0.10 & $5.83 \pm 0.09$ \\
\hline Acenaph thene & $5540 \pm 490$ & $0.0749 \pm 0.0020$ & 0.68 & $4.98 \pm 0.09$ \\
\hline Biphenyl & $15,800 \pm 700$ & $0.195 \pm 0.005$ & 0.62 & $5.02 \pm 0.05$ \\
\hline$C_{1}$-(biphenyls/acenaphthenes) (5) & $17,900 \pm 700$ & $0.0724 \pm 0.0013$ & 0.20 & $5.50 \pm 0.04$ \\
\hline Fluorene & $4940 \pm 380$ & $0.0377+0.0030$ & 0.38 & $5.22 \pm 0.11$ \\
\hline$C_{1}$-fluorenes (3) & $6640 \pm 180$ & $0.0186 \pm 0.0005$ & 0.14 & $5.66 \pm 0.04$ \\
\hline Phenanthrene & $10,800 \pm 1000$ & $0.0497 \pm 0.0015$ & 0.23 & $5.44 \pm 0.10$ \\
\hline Fluoranthene & $1590 \pm 120$ & $0.0016 \pm 0.0001$ & 0.05 & $6.11 \pm 0.09$ \\
\hline Pyrene & $7500 \pm 1000$ & $0.0050 \pm 0.0002$ & 0.03 & $6.28 \pm 0.14$ \\
\hline
\end{tabular}

*Values were not reported for components having $<80 \%$ of their mass in the aqueous phase.

tThe number of GC peaks observed for a set of isomers is given in parentheses.

dines and anilines were highly water soluble and for the most part did not have measurable $K_{\mathrm{D}}$ values. $\log K_{\mathrm{D}}$ values for less water soluble basic components, principally quinolines, ranged from 2.57 to 3.55. Herbes et al. (1983), also using CRM-1, reported $\log K_{\mathrm{D}} \mathrm{s}$ for $\left(\mathrm{C}_{0}-\mathrm{C}_{3}\right)$-phenols in the range of 0.3-2.3, and for $\left(\mathrm{C}_{0}-\mathrm{C}_{3}\right)$-anilines, 1.7-3.4.

Tables 4 and 5 give the chemical composition and distribution data for the neutral aromatic hydrocarbons and $\mathrm{S}-, \mathrm{O}-$ and $\mathrm{N}$-heterocycles, respectively. Alkyl-substituted isomers are grouped by alkyl carbon number. The aromatic hydrocarbons and $\mathrm{O}$ - and S-heterocycles consist primarily of 1- to 3-ring compounds and their alkylated derivatives. The neutral $\mathrm{N}$-heterocycles (azaarenes) consist almost entirely of $\left(\mathrm{C}_{0}-\mathrm{C}_{3}\right)$-indoles and $\left(\mathrm{C}_{0}-\mathrm{C}_{1}\right)$-carbazoles.

Overall, the aromatic hydrocarbon fraction was highly insoluble in water, with few components having more than $1 \%$ of their mass in the aqueous phase. $\log K_{\mathrm{D}}$ values ranged from 4.25 for toluene to 6.28 for pyrene. The indoles and carbazoles were significantly more soluble than the hydrocarbons owing to dipolar interactions between the heterocyclic nitrogen moiety and water, but still resided primarily in the oil phase. $\log K_{\mathrm{D}}$ values ranged from 2.36 for indole to 4.18 for $C_{1}$-carbazoles.

The two higher polarity cuts from the silica subfractionation of the neutral fraction were analyzed only gravimetrically. Table 1 shows that they were relatively minor fractions of the original oil. These higher polarity fractions were not analyzed for individual components primarily because they were not chemically homogeneous fractions and because they were generally not amenable to analysis by GC. In

Table 5. $\log K_{\mathrm{D}}$ values for heterocyclic components of CRM-1

\begin{tabular}{|c|c|c|c|c|}
\hline Compound & $\begin{array}{c}\text { Concentration } \\
\text { in raw CRM-1 } \\
\left(\mu \mathrm{gg}^{-1}\right)\end{array}$ & $\begin{array}{l}\text { Concentration } \\
\text { in aqueous } \\
\text { phase } \\
\left(\mathrm{mg} \mathrm{l}^{-1}\right)\end{array}$ & $\begin{array}{c}\text { Amount } \\
\text { transferred } \\
\text { to aqueous } \\
\text { phase } \\
(\%)\end{array}$ & $\log K_{D}^{*}$ \\
\hline Benzothiophene & $1120 \pm 80$ & $0.0240 \pm 0.0008$ & 1.1 & $4.78 \pm 0.08$ \\
\hline $\mathrm{C}_{1}$-benzothiophenes $(2) \dagger$ & $4100 \pm 200$ & $0.0348 \pm 0.0012$ & 0.42 & $5.18 \pm 0.06$ \\
\hline Dibenzothiophene & $950 \pm 70$ & $0.0043 \mp 0.0003$ & 0.23 & $5.45 \pm 0.11$ \\
\hline Dibenzofuran & $4420 \pm 600$ & $0.0345 \pm 0.0025$ & 0.39 & $5.21 \pm 0.15$ \\
\hline Diphenylether & $28,000 \pm 1200$ & $0.356 \pm 0.026$ & 0.63 & $5.00 \pm 0.09$ \\
\hline Indole & $2130 \pm 100$ & $3.14 \pm 0.01$ & 74 & $2.36 \pm 0.18$ \\
\hline $\mathrm{C}_{1}$-indoles (3) & $3020 \pm 90$ & $3.80 \pm 0.05$ & 61 & $2.62 \pm 0.08$ \\
\hline $\mathrm{C}_{2}$-indoles $(10)$ & $1520 \pm 70$ & $1.16 \pm 0.02$ & 38 & $3.02 \pm 0.08$ \\
\hline $\mathrm{C}_{3}$-indoles $(10)$ & $485 \pm 21$ & $0.156 \pm 0.003$ & 16 & $3.53 \pm 0.05$ \\
\hline Carbazoles (3) & $1930 \pm 180$ & $0.484 \pm 0.019$ & 12 & $3.65 \pm 0.11$ \\
\hline $\mathrm{C}_{1}$-carbazoles (4) & $1390 \pm 100$ & $0.113 \pm 0.003$ & 4.1 & $4.18 \pm 0.08$ \\
\hline
\end{tabular}

*Values were not reported for components having $<80 \%$ of their mass in the aqueous phase.

+ The number of GC peaks observed for a set of isomers is given in parentheses. 
fact, only a few percent of the methanol fraction (B4) mass could be analyzed by GC.

Four replicates of the raw CRM-1 samples and three replicates of the aqueous-oil samples were run through the preparation procedure and analyzed in duplicate by GC. The measured concentrations covered three orders of magnitude in both the coal-oil and aqueous-coal-oil samples. The average relative SD for all measurements was $5.2 \%$. Results of a PAH method recovery standard were pyrene, 97\%; chrysene, $95 \%$; and benzo(a)pyrene, $95 \%$.

\section{DISCUSSION}

The $K_{\mathrm{D}}$ values reported are particularly useful for modelling the behavior of hydrophobic compounds in multiphase aquatic systems. Because of the high ratio of aqueous volume to organic volume in most systems, most of the mass of nonhydrophobic organic components (for this discussion, $\log K_{\mathrm{D}}<2$ ) will exist in the aqueous phase and tend to remain there until degraded. Hydrophobic compounds, on the other hand, will tend to leave the water column and distribute themselves among the various organic phases available.

Partitioning of hydrophobic PAH and alkylated benzenes is of particular interest due to the abundance of these substances in coal oil and their toxicity and persistence in aquatic systems. The thermodynamics of partitioning of these two chemical groups can be examined through the $\log K_{\mathrm{D}} \mathrm{s}$ of homologs by correlating $\log K_{\mathrm{D}}$ with other thermodynamic properties. A large body of data exists on the solubilities of hydrocarbons in water and on their distribution coefficients in the octanol/water system, the thermodynamics of which have been investigated thoroughly.

The $K_{\mathrm{D}} \mathrm{s}$ measured in this study can be correlated thermodynamically to $S_{\mathrm{w}}$ s (Yalkowsky and Valvani, 1979, 1980; Chiou et al., 1982a; Miller et al., 1985) and, through linear-free-energy relationships, to $K_{\mathrm{ow}} \mathrm{s}$ (Leo et al., 1971; Campbell et al., 1983). The systems developed for predicting $K_{\mathrm{ow}}$ s from molecular structure can therefore be extended to important groups of compounds in the coal-oil/water system.

Correlation of $K_{D}$ with water solubility $\left(S_{w}\right)$

Following Chiou et al. (1982a), and substituting $K_{\mathrm{D}}$ for $K_{\text {ow }}$, the distribution coefficient can be related to the water solubility of a liquid solute by equation (2),

$$
\begin{aligned}
\log K_{\mathrm{D}}=-\log S_{\mathrm{w}}-\log V_{\mathrm{oil}}^{*} & \\
& -\log \gamma_{\text {oil }}^{*}+\log \left(\gamma_{\mathrm{w}}^{*} / \gamma_{\mathrm{w}}\right)
\end{aligned}
$$

$S_{\mathrm{w}}$ is the solubility of the liquid, or for solids, the subcooled liquid, $V_{\text {oil }}^{*}$ is the molar volume of the water-saturated oil phase, $\gamma_{\text {oil }}^{*}$ is the activity coefficient of the solute in the water-saturated oil phase, and $\gamma_{w}^{*}$ and $\gamma_{w}$ are the solute activity coefficients in the oil-saturated water phase and pure water, re-

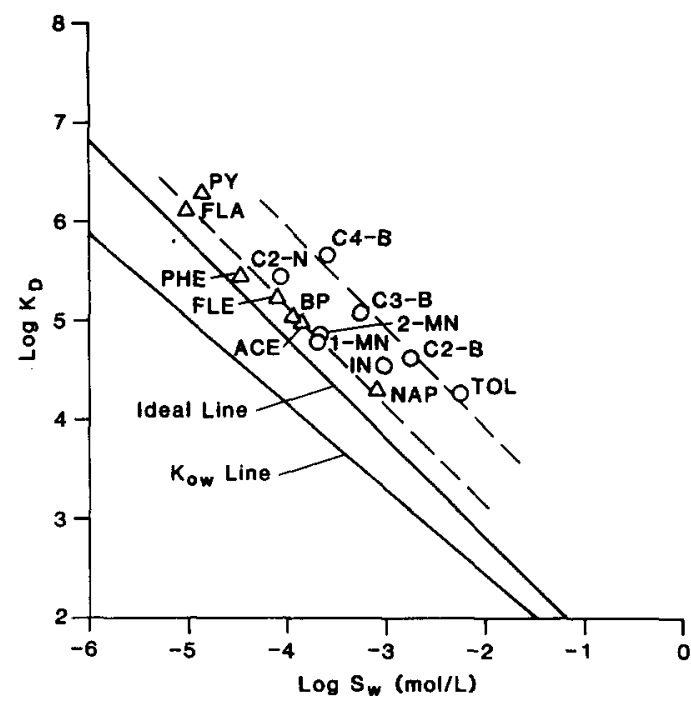

Fig. 2. Correlation between $\log K_{\mathrm{D}}$ and $\log S_{\mathrm{w}}$ for coal-oil PAH and alkylated benzenes. Identifications: TOL, toluene; $\left(\mathrm{C}_{2}-\mathrm{C}_{4}\right)-\mathrm{B}$, alkylated benzenes; NAP, naphthalene; $\mathrm{MN}$, methylnaphthalene; $\mathrm{C}_{2}-\mathrm{N}$, dialkylated naphthalenes; $A C E$, acenaphthene; BP, biphenyl; FLE, fluorene; PHE, phenanthrene; FLA, fluoranthene; PY, pyrene.

spectively. The subcooled liquid solubility can be obtained from the solubility of the solid through the ratio of the fugacities of the solid and reference (subcooled liquid) states which can be calculated using standard thermodynamic methods (Mackay and Shiu, 1977; Yalkowsky and Valvani, 1980; Chiou et al., 1982a).

Assuming that the activity coefficients in oilsaturated water are not significantly different from those in pure water, and the solute has ideal solubility in the water-saturated oil phase, the last terms in equation (2) drop out leaving a linear relationship between $\log K_{\mathrm{D}}$ and $\log S_{\mathrm{w}}$ with a theoretical slope of minus one and an intercept of $-\log V_{\text {oil }}^{*}$.

The relationships between $\log K_{\mathrm{D}}$ and $\log S_{\mathrm{w}}$ for PAH and alkylated benzenes from coal oil are shown in Fig. 2. Since many of the compounds included are solids at room temperature, solubilities of the hypothetical subcooled liquids are used (Mackay and Shiu, 1977; Chiou et al, 1982a). The ideal line in Fig. 2 is based on a molar volume of oil calculated from a density of $0.99 \mathrm{~g} \mathrm{ml}^{-1}$ and an estimated molecular weight of $150 \mathrm{~g} \mathrm{~mol}^{-1}$.

The regression line for the $\mathrm{PAH}$ in Fig. 2 is represented by equation (3),

$$
\begin{aligned}
& \log K_{\mathrm{D}}=-1.01 \log S_{\mathrm{w}}+ 1.12 \\
&(r=-0.979, n=7) .
\end{aligned}
$$

The slope of the correlation is nearly ideal. Chiou et al. (1982a) observed a slope lower than ideal $(-0.862)$ for the relationship between $\log K_{\text {ow }}$ and $\log S_{w}$ (Fig. 2) for a larger but similar set of compounds, which was attributed to increasing incompatibility of the solute with the water-saturated 
octanol phase (increasing $\gamma_{0}^{*}$ ) with increasing molecular weight, and, to a lesser extent, to an increasing enhancement of solute water solubility by dissolved octanol with increasing molecular weight.

A comparison of slopes indicates that for the coal-oil/water system the effects due to dissolved oil in the water phase and nonideality in the oil phase are not nearly as large as the analogous effects in the octanol/water systems. This would be expected from the low level of dissolved oil in the aqueous phase, and from the similarity of the solutes and the organic phase in the present experiment.

The data for the alkylated benzenes plotted in Fig. 2 present an interesting picture. The regression line for $\log K_{\mathrm{D}}$ vs $\log S_{\mathrm{w}}$ for $\mathrm{C}_{1}$ - to $\mathrm{C}_{4}$-benzenes is given by equation (4),

$$
\begin{aligned}
\log K_{\mathrm{D}}=-1.01 \log S_{\mathrm{w}}+ & 1.91 \\
& (r=-0.982, n=4) .
\end{aligned}
$$

The observed slope is very near ideal, but the observed $K_{\mathrm{D}} \mathrm{s}$ are about an order of magnitude higher than those of PAH of similar molecular weight. This unexpected result is not likely to be due to an analytical error since the alkylated benzenes were present in the same fraction as the PAH, but instead, must be a function of the physical properties of these compounds. From the related data for $\mathrm{C}_{2}$-naphthalenes and indan, it appears that the relative size of the alkyl functionality is important. The exact nature of this "alkylation effect," at this point, is unclear.

The magnitude of $\log K_{\mathrm{D}}$ in these correlations can be interpreted from the intercepts, which, from the previous discussion, correspond to $-\log V_{\text {oil }}^{*}$. From the density of the oil $\left(0.99 \mathrm{~g} \mathrm{ml}^{-1}\right)$, then, one can calculate the average molecular weight (MW) of the oil. The intercepts from the PAH and alkylated benzene correlations translate to average oil MWs of 75 and $12 \mathrm{~g} \mathrm{~mol}^{-1}$, respectively, which are reflected in their displacement from the ideal line ( $\mathrm{MW}=150 \mathrm{~g} \mathrm{~mol}^{-1}$ ).

The calculated MWs are clearly lower than the true value, which we have estimated from the inventory of analyzable components (60\% mass recovery). Assuming $150 \mathrm{~g} \mathrm{~mol}^{-1}$ is a reasonably accurate estimate, the calculated MW values are about half the ideal value using the PAH data, and only about a tenth of this value, using the alkylated benzene data. These discrepancies could arise in two ways. They could be real differences due to negative deviations from Raoult's law for the solutes in the oil phase, or they may be artificial differences arising from losses of solutes incurred on filtering (Eganhouse and Calder, 1976). We suspect the latter is the more important cause, particularly for $\mathrm{PAH}$, based on our observation in trial experiments that aqueous phase concentrations of PAH were sensitive to filter oil loading and filtering duration. Nonideality effects are somewhat more plausible for alkylated benzenes which show much greater deviations from ideality than the PAH, but such effects cannot be separated from filtering losses.

In the present experiment, every effort was made to clarify the oil/water mixture by mechanical means prior to filtering, however, some losses of hydrophobics to the filtering apparatus were inevitable. A reduction of solute aqueous concentrations by up to $50 \%$ would have a maximum impact of artificially increasing $\log K_{\mathrm{D}}$ s by 0.3 , which is a relatively small effect for the hydrophobic solutes concerned. The effect on $\log K_{\mathrm{D}}$ correlations should be minimal. Obviously, however, some care must be taken in interpreting the alkylated benzene data.

\section{Correlation of $K_{D}$ with $K_{o w}$}

The octanol/water reference system is widely accepted as the standard reference system for characterizing the partitioning behavior in biphasic systems. $K_{\text {ow }}$ values have been measured or estimated from molecular structure for thousands of organic compounds. Moreover, the system has broad applicability to solutes of wide ranging polarity, and the thermodynamics of the system have been studied in detail. Therefore, it is important that distribution coefficients measured in other systems be correlated to $K_{\text {ow }}$. Such correlations have been termed linear free energy relationships (Leo et al., 1971; Campbell et al., 1983).

In Fig. $3, \log K_{\mathrm{D}}$ values for alkylated benzenes and PAH (including indan and alkylated napthalenes) are plotted against $\log K_{\text {ow }}$. For both sets of compounds a very good correlation exists, although the two sets of data are, again, significantly displaced from one another. The empirical correlation for the PAH is as follows:

$$
\begin{array}{r}
\log K_{\mathrm{D}}=0.996 \log K_{\mathrm{ow}}+1.01 \\
\quad(r=0.996, n=12)
\end{array}
$$

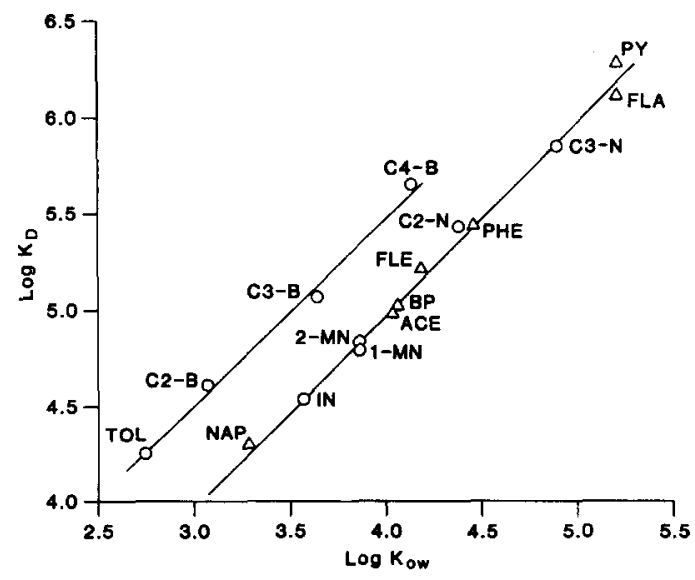

Fig. 3. Correlation between $\log K_{\mathrm{D}}$ and $\log K_{\text {ow }}$ for coal-oil $\mathrm{PAH}$ and alkylated benzenes. Refer to Fig. 2 caption for identifications. 
and for alkylated benzenes is:

$$
\begin{array}{r}
\log K_{\mathrm{D}}=0.937 \log K_{\mathrm{ow}}+1.53 \\
\quad(r=0.996, n=4) .
\end{array}
$$

As was the case for the solubility correlation, the alkylated benzenes exhibited higher than expected $\log K_{\mathrm{D}}$ s. The same discussion as to the possible sources of this discrepancy in the solubility correlation would apply here.

The strength of the correlation of $\log K_{\mathrm{D}}$ with $\log K_{\mathrm{ow}}$ is important as it ties the coal-oil/water system to the octanol/water system for which data are so widely available. To a very good approximation, for PAH,

$$
\log K_{\mathrm{D}}=\log K_{\mathrm{ow}}+1
$$

\section{Solubility and partitioning of mixtures}

When equilibrating a mixture of organic compounds, such as coal oil, with water, the possibility of cosolute effects on aqueous solubility must be considered. Because of the extremely low solubility of water in oil, it is not expected that dissolved water in the oil phase will have a measurable effect on solute activity coefficients in oil (Burris and MacIntyre, 1986). Even in the case of octanol/water partitioning in which water is present at a level of $2.3 \mathrm{M}$, its presence has only a small effect on solute solubility (Chiou et al., 1982a; Miller et al., 1985).

Likewise, cosolute effects in the aqueous phase are also expected to be small. In studies of the solubilities of mixture of chlorobenzenes and other hydrophobic organics, Banerjee (1984) reported that mixtures of related hydrophobic organics had near ideal behavior in the organic phase, and aqueous phase activity coefficients were unaffected by the presence of cosolutes. The same conclusions were drawn by Burris and MacIntyre (1986) from studies on various hydrocarbon mixtures, and by Munz and Roberts (1986) in studies on chlorinated hydrocarbons. Eganhouse and Calder (1976) observed a slightly enhanced $(\sim 10 \%)$ solubility of acenaphthene when dissolved with naphthalene and/or phenanthrene, but all other combinations of aromatic solids exhibited either no effect or reduced solubilities which could be attributed to the formation of solid solutions. Based on the observations of these investigators, cosolute effects in the coal-oil/water partitioning are believed to be insignificant.

For mixtures of liquids and solids in which the solids are dissolved in the liquids, as is the case with coal oil, the mixture behaves like a mixture of liquids. Banerjee (1984) found, using melting point corrections, that solutions of solid and liquid chlorobenzenes behaved ideally. Coal oil would be expected to behave in the same way.

\section{Activity coefficients $\left(\gamma_{w}\right)$}

Referring again to the discussion of Chiou et al.
Table 6. Calculated aqueous-phase activity coefficients for various aromatic hydrocarbons

\begin{tabular}{lcc}
\hline Compound & $\begin{array}{c}\text { Calculated } \\
\log \gamma_{w}\end{array}$ & $\begin{array}{c}\text { Reported } \\
\log \gamma_{w}\end{array}$ \\
\hdashline Toluene & 5.18 & 3.97 \\
Indan & 5.46 & $4.78 \dagger$ \\
Naphthalene & 5.23 & 4.83 \\
1-methylnaphthalene & 5.72 & $5.41 \ddagger$ \\
2-methylnaphthalene & 5.78 & $5.41 \ddagger$ \\
Acenaphthene & 5.91 & 5.54 \\
Biphenyl & 5.94 & 5.54 \\
Fluorene & 6.15 & 5.90 \\
Phenanthrene & 6.37 & 6.26 \\
Fluoranthene & 7.04 & 6.97 \\
Pyrene & 7.21 & 6.97 \\
\hline
\end{tabular}

*Source: Tsonopoulos and Prausnitz (1971).

+ Based on aqueous solubility (Mackay and Shiu. 1977).

¥Assuming a methyl group contribution of 0.58 .

(1982a) of the octanol/water system and applying the same approximations (mole fraction in each phase equals the product of the molar concentration, $C$, and molar volume, $V$ ), and substituting coal oil for octanol, the equilibrium condition is given by equation (7),

$$
K_{\mathrm{D}}=\frac{C_{0}}{C_{\mathrm{w}}}=\frac{\gamma_{w}^{*} V_{\mathrm{w}}^{*}}{\gamma_{0}^{*} V_{0}^{*}}
$$

where $C_{\mathrm{w}}$ and $C_{0}$, and $\gamma_{w}^{*}$ and $\gamma_{0}^{*}$ are the molar concentrations and activity coefficients of the solute in the water and oil phases, respectively, and $V_{w}^{*}$ and $V_{0}^{*}$ are the molar volumes of the two mutually saturated phases.

Using the estimated average molecular weight of the oil phase, $150 \mathrm{~g} \mathrm{~mol}^{-1}$, and the density to the raw oil, $0.99 \mathrm{~g} \mathrm{ml}^{-1}$, for that of the oil phase, $V_{0}^{*}$ assumes a value of $0.152 \mathrm{I} \mathrm{mol}^{-1}$. The aqueous phase activity coefficient, $\gamma_{w}^{*}$, can be calculated from equation (7), assuming $\gamma_{0}^{*}$ is unity, and substituting the molar volume of pure water for $V_{w}^{*}$.

The log of the water activity coefficients for several PAH calculated in this way are compared to those reported by Tsonopoulos and Prausnitz (1971) in Table 6. Except for toluene and indan, there is fairly good agreement between the two sets of values, and the agreement improves with increasing molecular weight. The agreement with literature values tends to support the assumptions of unit activity coefficients in the oil phase (with the exceptions of the alkylated benzenes) and the absence of cosolute effects in the aqueous phase. The aqueous phase activity coefficient, due to its insensitivity to temperature is the preferred parameter for correlating aqueous phase behavior and molecular properties (Tsonopoulos and Prausnitz, 1971).

\section{Correlations of $K_{D}$ or $\gamma_{w}$ with molecular structure}

The logarithms of infinite dilution activity coefficients for members of homologous series have long been correlated to molecular structure (Pierotti et al., 1959; Cratin, 1968; Leo et al., 1971; Tsonopoulos and Prausnitz, 1971; Harris et al., 1973; Mackay 


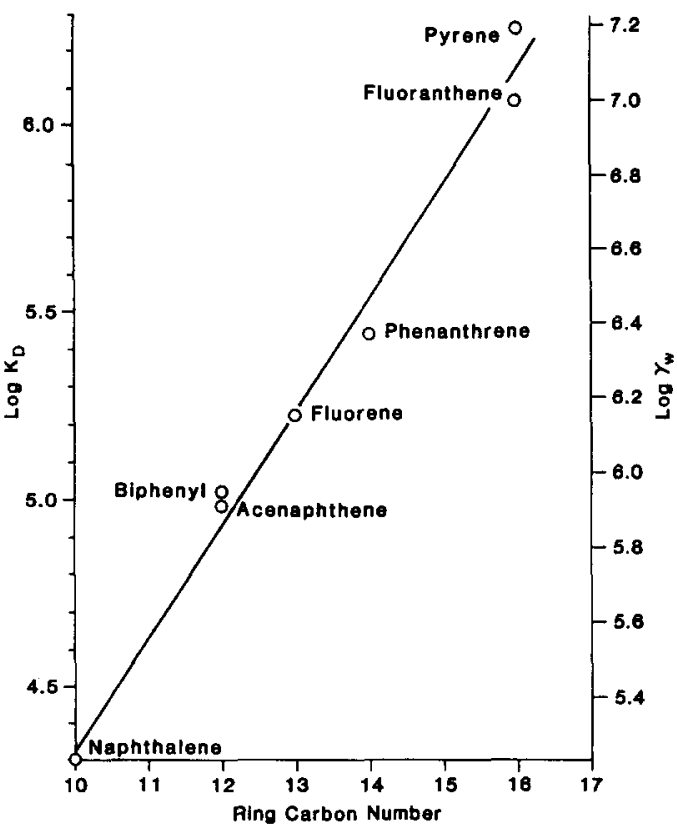

Fig. 4. Correlation between $\log K_{\mathrm{D}}$ and carbon number of coal-oil PAH.

and Shiu, 1977; Rekker, 1977; Yalkowsky and Valvani, 1979; Chiou et al., 1982b), thus providing a thermodynamic basis for assigning structural group contributions to activity coefficients and therefore to distribution coefficients. In early work by McAuliffe (1966) on hydrocarbons, solubility was correlated to solute molar volume. This theory was refined by subsequent investigators who correlated solubilities or distribution coefficients to solute cavity surface areas to account for such effects as branching (Hermann, 1971; Harris et al., 1973; Reynolds et al., 1974; Yalkowsky and Valvani, 1979; Leahy, 1986).

Distribution coefficients can be correlated to a number of solute carbon atoms $\left(n_{\mathrm{c}}\right)$ for families of homologs in coal oil. Figure 4 shows a linear relationship and the corresponding $\log \gamma_{w}, \log K_{\mathrm{D}}$ and $n_{\mathrm{c}}$ for unsubstituted PAH from 10 to 16 carbons. The regression line is represented by equation (8),

$$
\log K_{\mathrm{D}}=0.307 n_{\mathrm{c}}+1.26 \quad(r=0.993) .
$$

Tsonopoulos and Prausnitz (1971) reported a slope of 0.358 for $\log \gamma_{w}$ as a function of the $n_{c}$ for condensed PAH. The present plot includes acenaphthene and fluorene which each contain a nonaromatic carbon and biphenyl which is a nonrigid aromatic compound. Apparently these structural differences do not have a large enough effect on $\log \gamma_{w}$ to produce a significant deviation from linearity.

Given the strength of the correlation between $K_{\mathrm{D}}$ (or $K_{\mathrm{ow}}$ ) and $n_{\mathrm{c}}$ for condensed PAH, and the existence of a thermodynamic basis for such a correlation (correlations with cavity surface area), it is reasonable to extrapolate this relationship to PAH of higher $n_{\mathrm{c}}$. Table 7 presents the aqueous phase concentrations for several PAHs of environmental interest calculated from estimated $K_{\mathrm{D}} \mathrm{s}$ from equation (8) and their concentrations in CRM-1. The projected concentrations are at the $\mathrm{ng}^{-1}$ level, which are consistent with levels found in natural waters.

Since alkyl groups ( $-\mathrm{CH}_{2}-$ ) are responsible for a greater increase (by a factor of about two) in $\gamma_{w}$ than ring carbon groups (Mackay and Shiu, 1977), alkylated aromatics should be correlated separately. In Fig. $5, \log K_{\mathrm{D}}$ is correlated to the alkyl carbon number for alkylated benzenes, naphthalenes, quinolines and indoles. The slopes of the regression lines (alkyl group substituent effect) for the four sets of compounds are as follows: benzenes, $0.47(r=0.995)$; naphthalenes, $0.45 \quad(r=0.982)$; quinolines, 0.42 ; $(r=0.980)$; and indoles, $0.39(r=0.990)$.

Alkyl group substituent effects for the four sets of compounds are quite consistent and apparently decrease in a narrow range with increasing polarity of the parent molecule. This is perhaps due to mixed hydrophobic and hydrophilic interactions between polar heterocyclics and water, whereas, the hydrocarbons are capable of only hydrophobic interactions. The alkyl substituent effect for substituted benzenes of 0.47 is in good agreement with the value of 0.5 reported by Leo et al. (1971) for substituted benzenes in octanol/water. Pierotti et al. (1959) and Tsonopoulos and Prausnitz (1971) both reported a value of about 0.6 for the effect of benzene alkyl groups on $\gamma_{w}$.

The magnitude of the substituent effect for a given

Table 7. Estimated $\log K_{\mathrm{D}}$ values and projected aqueous concentrations of 4and 5-ring PAH from coal oil

\begin{tabular}{|c|c|c|c|c|}
\hline PAH compound & $\begin{array}{l}\text { Carbon } \\
\text { number }\end{array}$ & $\begin{array}{c}\text { CRM-1 } \\
\text { concentration } \\
\left(\mu \mathrm{gg}^{-1}\right)\end{array}$ & $\begin{array}{c}\text { Estimated } \\
\log K_{\mathrm{D}}\end{array}$ & $\begin{array}{c}\text { Projected } \\
\text { aqueous } \\
\text { concentration } \\
\left(\mu \mathrm{g} \mathrm{l}^{-1}\right)\end{array}$ \\
\hline 1,2-benzfluorene & 17 & $372 \pm 34$ & 6.48 & $0.16(0.11)_{+}^{+}$ \\
\hline 2,3-benzfluorene & 17 & $345 \pm 50$ & 6.48 & $0.15(0.08)_{+}^{+}$ \\
\hline Benz(a)anthracene & 18 & $214 \pm 30$ & 6.79 & 0.045 \\
\hline Chrysene & 18 & $411 \pm 33$ & 6.79 & 0.087 \\
\hline $\begin{array}{l}\operatorname{Benzo}(j+b)- \\
\text { fluoranthene }\end{array}$ & 20 & $238 \pm 17$ & 7.40 & 0.012 \\
\hline Benzo(e)pyrene & 20 & $196 \pm 23$ & 7.40 & 0.010 \\
\hline Benzo(a)pyrene & 20 & $118 \pm 16$ & 7.40 & 0.0061 \\
\hline
\end{tabular}

* Extrapolated from Fig. 2

+Calculated from estimated $\log K_{\mathrm{D}}$ and concentration in CRM-1.

$\ddagger$ Values determined previously by SIM mass spectrometry. 


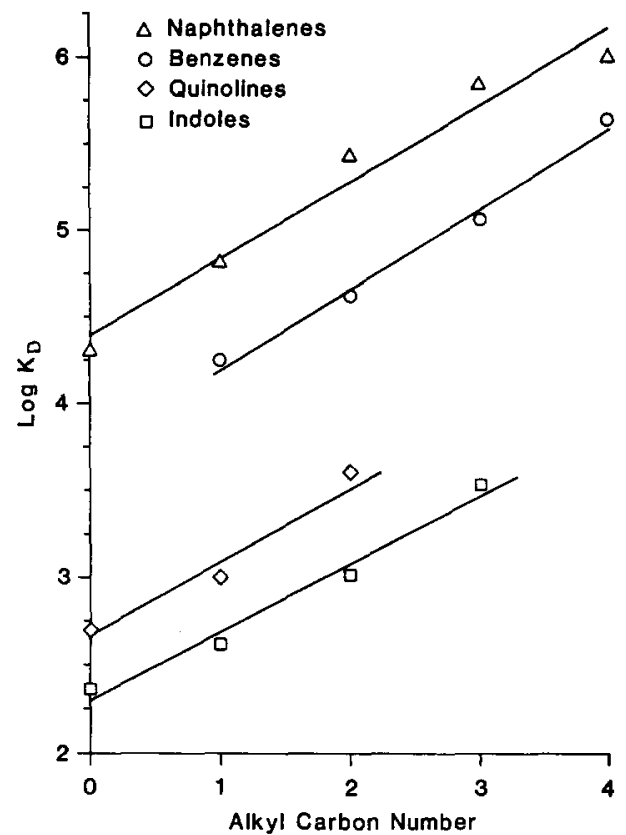

Fig. 5. Alkyl group substituent effect on $\log K_{\mathrm{D}}$ for various classes of coal-oil components.

functional group in a given biphasic system is the difference between the effects of the substituent on solute compatability with water and the organic phase (Chiou et al., 1982b). It is apparent that coal-oil and octanol exhibit similar properties in this respect, because of the similarity of the alkyl substituent effect in both systems.

\section{CONCLUSIONS}

$K_{\mathrm{D}}$ values vary widely within and between major classes of components of CRM-1, a coal-oil reference material. PAHs of environmental concern have high $K_{\mathrm{D}}$ values, which reflect their tendency to accumulate in the organic phases of aquatic systems. Such behavior has important consequences regarding the fate and effects of coal-oil PAH. The tendency of PAH to accumulate in bottom sediments and living organisms increases their persistence and toxicity in aquatic systems, while reducing their availability for photodegradation (Picel et al, , 1984) and volatilization.

Coal-oil/water partitioning behaviors of two important classes of aromatic hydrocarbons were examined in detail. It was found that $K_{\mathrm{D}}$ values for alkylated benzenes and PAH were well correlated with aqueous solubility and octanol-water partition coefficients. It was also revealed that alkylated benzenes had higher $K_{\mathrm{D}} \mathrm{s}$ than would be expected from solubility data, or from values for PAH of similar molecular weight. The reasons for this observation are unclear. Perhaps further studies in this area would shed light on this matter.

PAH which are ordinarily solids at room temperature were found to behave like liquids in the liquid/coal-oil mixtures. That is, $K_{\mathrm{D}}$ data for coal-oil $\mathrm{PAH}$ which are room temperature solids are correlated thermodynamically to their hypothetical subcooled liquid states, not their solid states.

Data for homologs revealed strong correlations of $\log K_{\mathrm{D}}$ with chemical structure. Such correlations have been explained in terms of the increase in cavity surface area associated with the addition of a homologous group. Further data showed that the alkyl substituent effect was quite consistent over a range of chemical classes with varying polarity. The correlations developed here should be applicable to predicting $K_{\mathrm{D}} \mathrm{s}$ of aromatic hydrocarbons of various structures from coal liquids in general.

Acknowledgements-The authors thank Paul Doskey and three anonymous reviewers for helpful suggestions which significantly improved the paper. This work was supported by the U.S. Department of Energy, Assistant Secretary for Fossil Energy, under Contract W-31-109-Eng-38.

\section{REFERENCES}

Banerjee S. (1984) Solubility of organic mixtures in water. Envir. Sci. Technol. 18, 587-591.

Burris D. R. and MacIntyre W. G. (1986) A thermodynamic study of solutions of liquid hydrocarbon mixtures in water. Geochim. cosmochim. Acta 50, 1545-1549.

Campbell J. R., Luthy R. G. and Corrondo M. J. T. (1983) Measurement and prediction of distribution coefficients for wastewater aromatic solutes. Envir. Sci. Technol. 17, 582-590.

Chiou C. T. (1985) Partition coefficients of organic compounds in lipid-water systems and correlations with fish bioconcentration factors. Envir. Sci. Technol. 19, 57-62.

Chiou C. T., Schmedding D. W. and Manes M. (1982a) Partitioning of organic compounds in octanol-water systems. Envir. Sci. Technol, 16, 4-10.

Chiou C. T., Schmedding D. W., Block J. H. and Manes M. (1982b) Substituent contribution to the partition coefficients of substituted benzenes in solvent-water mixtures. J. Pharm. Sci. 71, 1307-1309.

Chiou C. T., Freed V. H., Schmedding D. W. and Kohnert R. L. (1977) Partition coefficient and bioaccumulation of selected organic chemicals. Envir. Sci. Technol. 11, 475-478.

Cratin P. D. (1968) Partitioning at the liquid-liquid interface. Ind. Engng Chem. 60, 14-19.

Dauble D. D., Fallon W. E., Gray R. H. and Bean R. M. (1981) Chronic toxicity of water-soluble fractions of fresh and water-leached solvent-refined coal (SRC-II) liquids to a freshwater benthic invertebrate. In Coal Conversion and the Environment: Chemical, Biomedical, and Ecological Considerations (Edited by Mahlum D. D., Gray R. H. and Felix W. D.), pp. 212-222. U.S. Department of Energy, Washington, D.C., CONF-80-1039.

Eganhouse R. P. and Calder J. A. (1976) The solubility of medium molecular weight aromatic hydrocarbons and the effects of hydrocarbon co-solute and salinity. Geochim. cosmochim. Acta. 40, 555-561.

Giddings J. M. and Washington J. N. (1981) Coalliquefaction products, shale, oil, and petroleum -Acute toxicity of freshwater algae. Envir. Sci. Technol. 15, 106-108.

Giddings J. M., Herbes S. E. and Gehrs C. W. (1985) Coal-liquifaction products. Envir. Sci. Technol. 19, 14-18. Gray R. H., Hanf R. W., Dauble D. D. and Skalski J. R. (1982) Chronic effects of a coal liquid on a freshwater alga, Selenastrum capricornutum. Envir. Sci. Technol. 16, 225-229. 
Hansch C. (1980) The role of partition coefficient in environmental toxicity. In Dynamics, Exposure, and Hazard Assessment of Toxic Chemicals (Edited by Haque R.), pp. 273-286. Ann Arbor Science, Ann Arbor, Mich.

Harris S. M. J., Higuchi T. and Rytting J. H. (1973) Thermodynamic group contributions from ion pair extraction equilibria for use in the prediction of partition coefficients. Correlation of surface area with group contributions. J. phys. Chem. 77, 2694-2703.

Herbes S. E., Southworth G. R. and Allen C. P. (1983) Rates of dissolution of constituent organic contaminants from coal liquifaction oil films into water. Wat. Res. 17, $1639-1646$.

Hermann R. B. (1971) Theory of hydrophobic bonding. II. The correlation of hydrocarbon solubility in water with solvent cavity surface area. J. phys. Chem. 76, 2754-2759.

Leahy D. E. (1986) Intrinsic molecular volume as a measure of the cavity term in linear solvation energy relationships: octanol-water partition coefficients and aqueous solubilities. J. Pharm. Sci. 75, 629-636.

Leo A., Hansch C. and Elkins D. (1971) Partition coefficients and their uses. Chem. Rev. 71, 525-616.

Mackay D. and Shiu W. Y. (1977) Aqueous solubility of polynuclear aromatic hydrocarbons. J. chem. Engng Data 22, 399-402.

McAuliffe C. D. (1966) Solubility in water of paraffin, cycloparaffin, olefin, acetylene, cycloolefin, and aromatic hydrocarbons. J. phys. Chem. 70, 1267-1275.

Miller M. M., Ghodbane S., Wasik S. P., Tewari Y. B. and Martire D. E. (1984) Aqueous solubilities, octanol/water partition coefficients, and entropies of melting of chlorinated benzenes and biphenyls. J. chem. Engng Data 29, 184-190.

Miller M. M., Wasik S. P., Huang G.-L., Shiu W.-Y. and Mackay D. (1985) Relationships between octanol-water partition coefficients and aqueous solubility. Envir. Sci. Technol. 19, 522-529.

Munz C. and Roberts P. V. (1986) Effects of solute concentration and cosolvents on the aqueous activity coefficient of halogenated hydrocarbons. Envir. Sci. Technol. 20, 830-836.

Neely W. B., Branson D. R. and Blau G. E. (1974) Partition coefficients to measure bioconcentration potential of organic chemicals in fish. Envir. Sci. Technol. 8, 1113-1115.

Picel K. C. (1985) Photolytic and partitioning behavior of polynuclear aromatic compounds, aromatic amines, and phenols in aqueous coal oil. Ph.D. thesis, University of Michigan, Ann Arbor, Mich.
Picel K. C., Stamoudis V. C. and Simmons M. S. (1984) Photolysis rates of selected polynuclear aromatic hydrocarbons in aqueous coal-oil systems. In Polynuclear Aromatic Hydrocarbons: Mechanisms, Methods, and Metabolism, Proc. 8th int. Symp. (Edited by Cooke, M. and Dennis, A. J.), pp. 1013-1028. Battelle Press, Columbus, Ohio.

Pierotti G. J., Deal C. H. and Derr E. L. (1959) Activity coefficients and molecular structure. Ind. Engng Chem. 51, 95-102.

Rekker R. F. (1977) The Hydrophobic Fragmental Constant. Elsevier, Amsterdam.

Reynolds J. A., Gilbert D. B. and Tanford C. (1974) Empirical correlation between hydrophobic free energy and aqueous cavity surface area. Proc. natn. Acad. Sci. U.S.A. 71, 2925-2927.

Southworth G. R. and Keller J. L. (1984) Partitioning of naphthalene, methylnaphthalenes and biphenyl between wastewater treatment sludges and water. Envir. Toxic. Chem. 3, 575-582.

Stamoudis V. C. and Luthy R. G. (1980) Determination of biological removal of organic constituents in quench waters from high-Btu coal-gasification pilot plants. Wat. Res. 14, 1143-1156.

Tong H. Y. and Karasek F. W. (1984) Flame ionization detector response factors for compound classes in quantitative analysis of complex organic mixtures. Analyt. Chem. 56, 2124-2128.

Tsonopoulos C. and Prausnitz J. M. (1971) Activity coefficients of aromatic solutes in dilute aqueous solutions. Ind. Engng Chem. Fundam. 10, 593-600.

Walters R. W. and Luthy R. G. (1984a) Equilibrium adsorption of polycyclic aromatic hydrocarbons from water onto activated carbon. Envir. Sci. Technol. 18, 395-403.

Walters R. W. and Luthy R. G. (1984b) Liquid/suspended solid phase partitioning of polycyclic aromatic hydrocarbons in coal-coking wastewaters. Wat. Res. 18, 795-809.

Yalkowsky S. H. and Valvani S. C. (1979) Solubilities and partitioning 2. Relationships between aqueous solubilities, partition coefficients, and molecular surface areas of rigid aromatic hydrocarbons. J. Chem. Engng Data 24, 127-129.

Yalkowsky S. H. and Valvani S. C. (1980) Solubility and partitioning. I: solubility of nonelectrolytes in water. $J$. Pharm. Sci. 69, 912-922. 